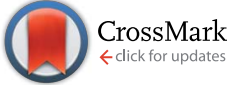

Cite this: Chem. Sci., 2017, 8, 1862

Received 18th November 2016 Accepted 23rd December 2016

DOI: $10.1039 / \mathrm{c} 6 \mathrm{sc05092a}$

www.rsc.org/chemicalscience

\section{Neutral chiral cyclopentadienyl $\mathrm{Ru}(\mathrm{II}) \mathrm{Cl}$ catalysts enable enantioselective [2+2]-cycloadditions $\dagger$}

\begin{abstract}
D. Kossler and N. Cramer*
Cyclopentadienyl ruthenium(॥) complexes with a large number of available coordination sites are frequently used catalysts for a broad range of transformations. To be able to render these transformations enantioselective, we have designed a chiral neutral $\mathrm{Cp}^{\times} \mathrm{Ru}(\|) \mathrm{Cl}$ complex basing on an atropchiral cyclopentadienyl $\left(\mathrm{Cp}^{\mathrm{x}}\right)$ ligand which is accessed in a streamlined $\mathrm{C}-\mathrm{H}$ functionalisation approach. The catalyst displays excellent levels of reactivity and enantioselectivity for enantioselective [2+2]-cycloadditions leading to strained chiral cyclobutenes, allowing for catalyst loadings as low as 1 mol\%. A very strong counterion effect of a bound chloride anion transforms the corresponding unselective cationic complex into a highly enantioselective neutral version. Moreover, by adding norbornadiene at the end of the reaction the catalyst can be recovered and subsequently reused.
\end{abstract}

\section{Introduction}

Homogenous ruthenium complexes constitute a cornerstone of modern transition-metal catalysis. ${ }^{1}$ Besides metathesis catalysts $^{2}$ and complexes employed for hydrogenations, ${ }^{3}$ cyclopentadienyl (Cp) or pentamethylcyclopentadienyl (Cp*) ruthenium(II) complexes, in particular $\mathrm{CpRu}\left(\mathrm{CH}_{3} \mathrm{CN}\right)_{3} \mathrm{PF}_{6}$ and $\mathrm{Cp} * \mathrm{Ru}(\mathrm{COD}) \mathrm{Cl}$ (COD = 1,5-cyclooctadiene), are highly valuable catalysts for atom-economic carbon-carbon and carbonheteroatom bond formations. ${ }^{4}$ One reason is their high number of available and freely accessible coordination sites. However, this has rendered the design of chiral versions challenging. ${ }^{5}$ Recently, we introduced chiral $\mathrm{Cp}$ ligands $\left(\mathrm{Cp}^{\mathrm{x}}\right)^{6}$ with the cyclopentadienyl group being the only point of coordination. These developments provided cationic $\mathrm{Cp}^{\mathrm{x}} \mathrm{Ru}(\mathrm{II})$ complexes able to mimic Trost's $\mathrm{CpRu}\left(\mathrm{CH}_{3} \mathrm{CN}\right)_{3} \mathrm{PF}_{6}$ catalyst. ${ }^{7}$ Complementary to this positively charged $\mathrm{CpRu}^{+}$fragment, neutral $\mathrm{Ru}(\mathrm{II})$ complexes catalyse different sets of transformations. In this domain, Cp* Ru(COD)Cl is the most versatile. ${ }^{8}$ Thus, a chiral version of this catalyst would be of great value. The bound halide ion is of critical importance and its role is going far beyond being only a bystander by occupying a coordination site, but altering the catalytic properties of the metal. ${ }^{9}$ Recently, the influence of the polarized $[\mathrm{Ru}-\mathrm{Cl}]$ fragment has been subject to detailed investigations by Fürstner, showing the ability to preorganize certain substrates and exert crucial influence on the

Laboratory of Asymmetric Catalysis and Synthesis, Institute of Chemical Sciences and Engineering, Ecole Polytechnique Fédérale de Lausanne, EPFL SB ISIC LCSA, BCH 4305, CH-1015 Lausanne, Switzerland.E-mail: nicolai.cramer@epfl.ch

$\dagger$ Electronic supplementary information (ESI) available: Experimental procedures and characterization of all new compounds. CCDC 1499170 and 1499171. For ESI and crystallographic data in CIF or other electronic format see DOI: 10.1039/c6sc05092a reaction. ${ }^{10}$ Synthetically it is very attractive to form in situ neutral chiral $\mathrm{Ru}$ (II) complexes by reaction of the corresponding cationic $\mathrm{Cp}^{\mathrm{x}} \mathrm{Ru}(\mathrm{II})$ complex 1 with a suitable coordinating anion (Fig. 1). One can use the same complex stock for a much broader set of transformations and conveniently interrogate possible counterion effects. ${ }^{9}$ This gives a complex with labile MeCN groups that easily dissociate. While isolated neutral $\mathrm{Ru}$ (II) complexes with tightly bound dienes are beneficial for the complex stability and storage, they reduce reactivity due to the required diene dissociation for the formation of catalytically active species. Ideally, the same chiral ligand could be used, increasing the overall generality and value of the established backbone design.

Among the many reactions catalysed by gold-standard complex $\mathrm{Cp} * \mathrm{Ru}(\mathrm{COD}) \mathrm{Cl}$ - the formal [2+2]-cycloaddition between bicyclic alkenes and alkynes is an attractive benchmark transformation. ${ }^{11}$ The reaction provides a unique access to strained cyclobutenes ${ }^{12}$ which are very attractive intermediates

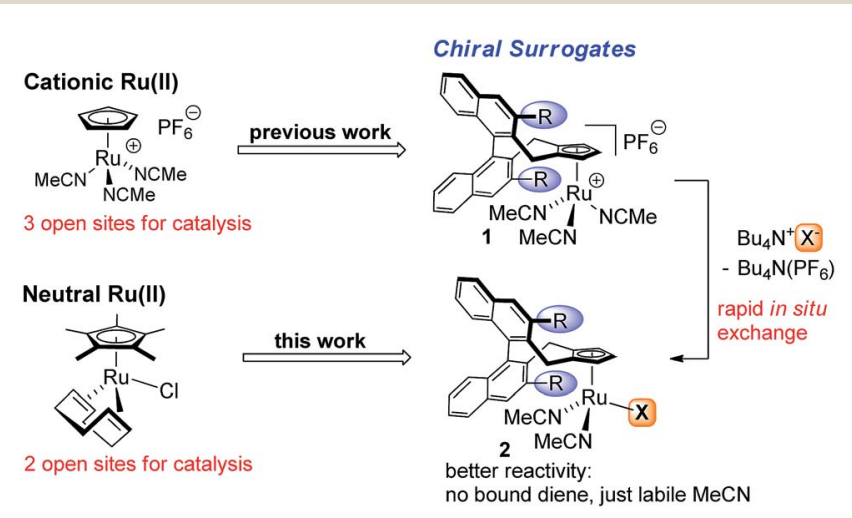

Fig. 1 Powerful cationic and neutral CpRu(॥) catalysts and their chiral $C \mathrm{p}^{\mathrm{x}}$ surrogates for asymmetric catalysis. 
for various valuable follow-up transformations. ${ }^{13}$ While its mechanism ${ }^{14}$ and the reactivity of different substrates ${ }^{15}$ have been investigated, no catalytic enantioselective Ru-catalysed $[2+2]$ cycloaddition could be realised until now due to the lack of any suitable chiral $\mathrm{CpRu}$ (II) catalysts. Tam reported a diastereoselective version using chiral alkynes. ${ }^{16}$ Currently, an enantioselective transformation is only known for a $\mathrm{Rh}(\mathrm{I})$-catalyst system with a significant substrate dependence of the enantioselectivity ${ }^{17}$ and an $\operatorname{Ir}(\mathrm{I})$-catalysed reaction which is restricted to benzo oxabicyclic alkenes and terminal alkynes. ${ }^{18}$

\section{Results and discussion}

Initially, the envisioned transformation was investigated with norbornene 3a and alkyne 4a (Scheme 1). Exposure of the reactants to $5 \mathrm{~mol} \%$ of the cationic $\mathrm{Cp}^{\mathrm{x}} \mathrm{Ru}(\mathrm{II})$ complex $1 \mathrm{a}$ resulted in a rapid and clean conversion, giving cyclobutene 5aa in $98 \%$ yield after $60 \mathrm{~min}$ reaction time at $0{ }^{\circ} \mathrm{C}$ (entry 1 ). Despite the excellent reactivity of the cationic complex, no stereoinduction was observed, giving racemic cyclobutene $\mathbf{5 a a}$. Notably, under these conditions the standard achiral catalyst, $\mathrm{Cp} * \mathrm{Ru}(\mathrm{COD}) \mathrm{Cl}$, displayed almost no reactivity at all, requiring $20 \mathrm{~h}$ for the reaction to go to completion at ambient temperature. This highlights the superior reactivity of this chiral $\mathrm{Cp}^{\mathrm{x}} \mathrm{Ru}(\mathrm{II})$ catalyst. A dramatic improvement was observed when chloride anions were added to form in situ a neutral $\mathrm{Ru}$ (II) complex. ${ }^{19}$ The catalyst maintained its superb reactivity, now paired with excellent enantioselectivity, producing 5aa in $96.5: 3.5$ er.

Intrigued by this dramatic selectivity enhancement, we then evaluated a range of additional anions in this transformation (Table 1). ${ }^{9}$ Bromide can replace chloride, providing largely comparable results (entry 3). However, an iodide diminished the reactivity, either due to its larger size or by altering the electronic properties of the ruthenium center (entry 4). Fluoride completely abolished the reactivity of the catalyst, as did the pseudohalides cyanide and azide (entries 5-7). Moreover, nitrate as well as acetate anions were not suitable (entries 8-9),

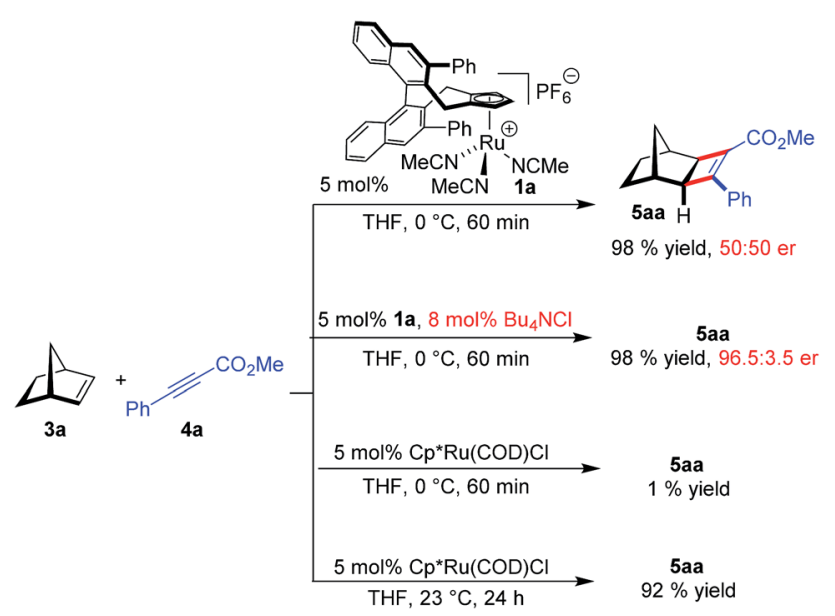

Scheme 1 Very strong counteranion effect on the enantioselectivity of cyclobutene product $5 \mathrm{aa}$.
Table 1 Influence of the counterion on the Ru(II) complex on reactivity and selectivity ${ }^{a}$

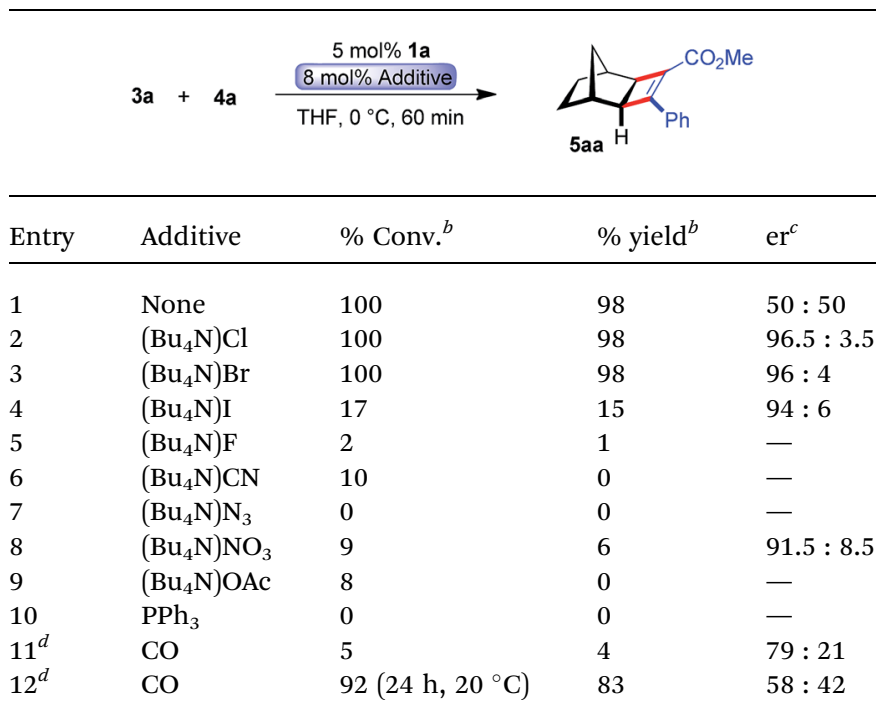

${ }^{a} 37.5 \mu \mathrm{mol} 3 \mathrm{a}, 25 \mu \mathrm{mol}$ 4a, $2.0 \mu \mathrm{mol}$ additive, $1.25 \mu \mathrm{mol} 1 \mathrm{aa}, 0.3 \mathrm{M}$ in THF, $0{ }^{\circ} \mathrm{C}, 60 \mathrm{~min} .{ }^{b}$ Determined by ${ }^{1} \mathrm{H}$-NMR with an internal standard. ${ }^{c}$ Determined by HPLC with a chiral stationary phase. ${ }^{d}$ With preformed complex.

likewise a neutral bound phosphine inhibited the reaction completely (entry 10). The reaction still proceeded with the corresponding $\mathrm{Cp}^{\mathrm{x}} \mathrm{Ru}(\mathrm{II})$ carbonyl complex, however much slower and less selective (entries 11-12). These results demonstrate the unique match of the chloride anion for functionality tuning of the ruthenium catalyst.

The influence of the ortho-substituents $\mathrm{R}$ of the ligand backbone were investigated next (Table 2). While their influence on the enantioselectivity was not very pronounced, the nature of the $\mathrm{R}$ groups had a large effect on the reaction rate. After $60 \mathrm{~min}$ reaction time, complexes $\mathbf{1 b}$ (3,5-xylyl) or 1d (4-methoxyphenyl),

Table 2 Performance of different chiral $\mathrm{Cp}^{\times}$ligands ${ }^{a}$

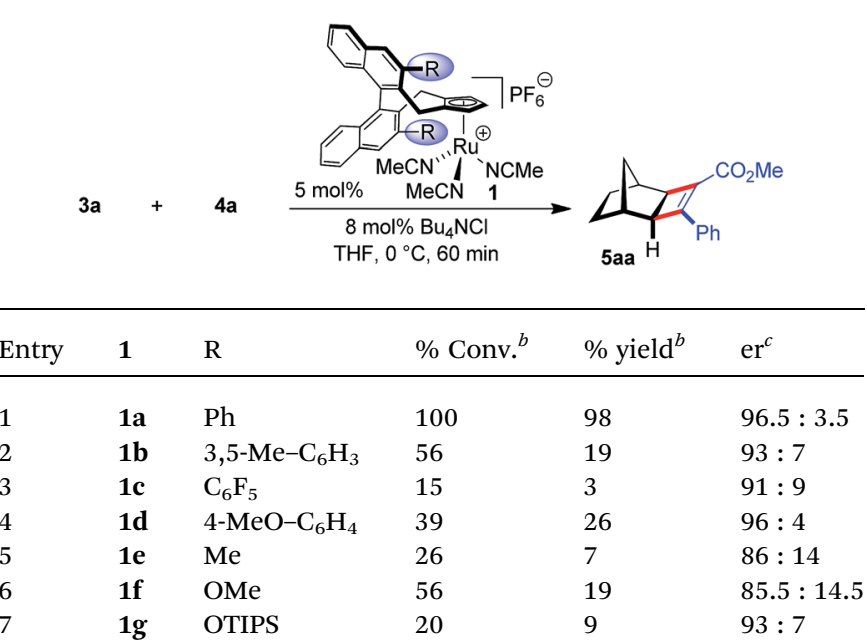

${ }^{a} 37.5 \mu \mathrm{mol} 3 \mathrm{a}, 25 \mu \mathrm{mol} 4 \mathrm{a}, 2.0 \mu \mathrm{mol} \mathrm{Bu}_{4} \mathrm{NCl}, 1.25 \mu \mathrm{mol} \mathrm{1,0}, 0.3 \mathrm{M}$ in THF, $0{ }^{\circ} \mathrm{C}, 60$ min. ${ }^{b}$ Determined by ${ }^{1} \mathrm{H}-\mathrm{NMR}$ with an internal standard. ${ }^{c}$ Determined by HPLC with a chiral stationary phase. 
revealed a significant reduction in reactivity and yield (entries 1-4) compared to the parent complex 1a. Smaller ligands like 1e or 1f (entries 5-6) display lower reactivity which leads to the assumption that the phenyl groups help to pre-organise the substrates for enhanced reaction rate. The difference in electronic properties of the $\mathrm{Ru}$ center for different $\mathrm{Cp}^{\mathrm{x}}$ ligands is very small. ${ }^{20}$

With $\mathrm{Ph}-\mathrm{Cp}^{\mathrm{x}}$ being a uniquely efficient ligand in ruthenium catalysis, we aimed to shorten its synthesis (Scheme 2). Our previous discovery route was based on a rather lengthy diversity oriented strategy, giving several streamlining opportunities. ${ }^{6 c, 21}$ Bis-carboxylic acid $6^{22}$ serves as directing group suited for Pd(II)-catalysed ortho-functionalisations, ${ }^{23}$ and coupling with iodobenzene would deliver 7. Biaryls are demanding substrates for such transformations, especially when a clean double functionalisation is required. Ligandless conditions ${ }^{\mathbf{2 4}}$ were not very efficient, giving mixtures of starting material, mono- and diarylated products. Using Yu's mono-protected amino acid ligands (MPAA) ${ }^{25}$ improved the efficiency significantly. For instance, $N$-acetyl glycine yielded bis-arylated product 7 in $69 \%$ yield. Subsequent reduction and substitution of the resulting benzylic alcohol provided bis-bromide 8. Annulation of the $\mathrm{Cp}$ group and complexation yields air- and moisture-stable complex 10, from which 1a can be rapidly generated. ${ }^{7}$ With this approach, the ligand is synthesised in only four steps, cutting the previous step-count by half.

The scope for the enantioselective Ru-catalysed cyclobutene formation was explored (Table 3). ${ }^{\mathrm{i}}$ Propyl or ${ }^{t}$ butyl propiolates increased the enantioselectivity to $98: 2$ er (entries 2-3). Even a free carboxylic acid (4e) was converted smoothly (entry 5). A ketone substrate reacted with somewhat lower enantioselectivity (entry 6). $\mathrm{R}^{1}$ can be a substituted arene or heteroarene (entry 7-11). The absolute configuration of 5ag was determined by X-ray crystallographic analysis after saponification to the corresponding free carboxylic acid. Besides arenes, vinyl or alkyl groups at the $\mathrm{R}^{1}$ position provide cyclobutenes (entries 12-14). Norbornadiene and benzo-fused derivatives 3 provided the cyclobutenes with similar enantioselectivity (entries 15-16). For $3 \mathbf{e}$ and $\mathbf{3 f}$, the exo/endo orientation of the substituents $\mathrm{R}^{3}$ was important for the reactivity (entries 18-19). Moreover, a heteroatom was tolerated in the bridge position, leading to oxy-bridged compound 5gc (entry 20). However, less strained

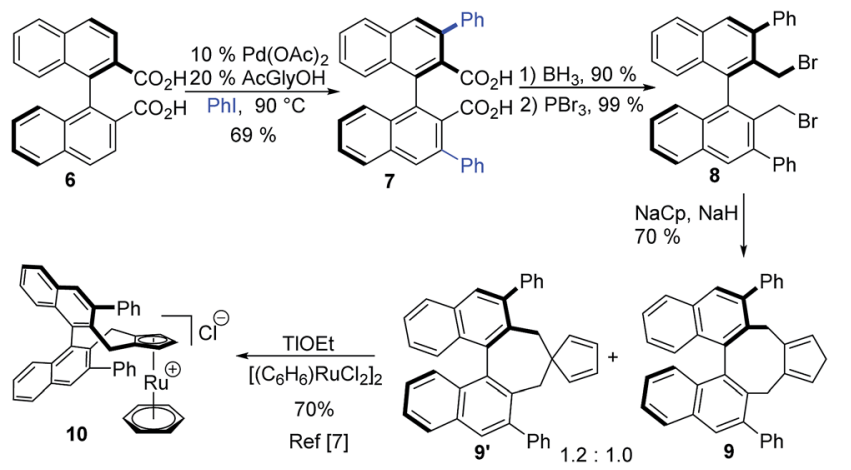

Table 3 Scope of the asymmetric [2+2] cycloaddition with neutral Ru(II) complex ${ }^{a}$

\begin{tabular}{|c|c|c|c|c|}
\hline Entry & & 5 & $\%$ yield $^{b}$ & $\mathrm{er}^{c}$ \\
\hline 1 & $5 \mathbf{a a}$ & $\mathrm{R}^{1}=\mathrm{Ph}, \mathrm{R}^{2}=\mathrm{CO}_{2} \mathrm{Me}$ & 97 & $96.5: 3.5$ \\
\hline 2 & $5 \mathbf{a b}$ & $\mathrm{R}^{1}=\mathrm{Ph}, \mathrm{R}^{2}=\mathrm{CO}_{2}{ }^{\mathrm{i}} \mathrm{Pr}$ & 86 & $98: 2$ \\
\hline 3 & 5 ac & $\mathrm{R}^{1}=\mathrm{Ph}, \mathrm{R}^{2}=\mathrm{CO}_{2}{ }^{t} \mathrm{Bu}$ & 80 & $98: 2$ \\
\hline 4 & $5 a d$ & $\mathrm{R}^{1}=\mathrm{Ph}, \mathrm{R}^{2}=\mathrm{CO}_{2} \mathrm{Ph}$ & 76 & $97: 3$ \\
\hline 5 & $5 \mathbf{a e}$ & $\mathrm{R}^{1}=\mathrm{Ph}, \mathrm{R}^{2}=\mathrm{CO}_{2} \mathrm{H}$ & 89 & $94: 6$ \\
\hline 6 & 5 af & $\mathrm{R}^{1}=\mathrm{Ph}, \mathrm{R}^{2}=\mathrm{C}(\mathrm{O}) \mathrm{Ph}$ & 98 & $75.5: 24.5$ \\
\hline 7 & $5 a g$ & $\mathrm{R}^{1}=3-\mathrm{Br}-\mathrm{Ph}, \mathrm{R}^{2}=\mathrm{CO}_{2} \mathrm{Me}$ & 85 & $97.5: 2.5$ \\
\hline 8 & $5 \mathbf{a h}$ & $\mathrm{R}^{1}=4-\mathrm{NO}_{2}-\mathrm{Ph}, \mathrm{R}^{2}=\mathrm{CO}_{2} \mathrm{Me}$ & 40 & $89.5: 10.5$ \\
\hline 9 & 5ai & $\mathrm{R}^{1}=4-\mathrm{OMe}-\mathrm{Ph}, \mathrm{R}^{2}=\mathrm{CO}_{2} \mathrm{Me}$ & 91 & $98: 2$ \\
\hline 10 & $5 \mathbf{a j}$ & $\mathrm{R}^{1}=3-\mathrm{Me}-\mathrm{Ph}, \mathrm{R}^{2}=\mathrm{CO}_{2} \mathrm{Me}$ & 93 & $96.5: 3.5$ \\
\hline 11 & 5ak & & 96 & $97.5: 2.5$ \\
\hline $12^{d}$ & 5 al & & 88 & $83: 17$ \\
\hline $13^{d}$ & 5 am & & 91 & $89: 11$ \\
\hline $14^{d}$ & 5an & & 70 & $86: 14$ \\
\hline $15^{d}$ & $5 b c$ & & 81 & $97: 3$ \\
\hline 16 & $5 \mathrm{cc}$ & & 91 & $98: 2$ \\
\hline 17 & $5 \mathrm{dc}$ & & 96 & $95: 5$ \\
\hline 18 & $5 e c$ & $\mathrm{Me}$ & 97 & $99: 1$ \\
\hline 19 & $5 \mathrm{fc}$ & $\mathrm{MeO}^{\prime}$ & 39 & $90.5: 9.5$ \\
\hline 20 & $5 \mathrm{gc}$ & & 87 & $80: 20$ \\
\hline
\end{tabular}

${ }^{a} 0.15 \mathrm{mmol} 3 \mathrm{x}, 0.10 \mathrm{mmol} 4 \mathrm{y}, 8.0 \mu \mathrm{mol}\left(\mathrm{Bu}_{4} \mathrm{~N}\right) \mathrm{Cl}, 5.0 \mu \mathrm{mol} 1 \mathrm{a}, 0.3 \mathrm{M}$ in THF, $0{ }^{\circ} \mathrm{C}, 60$ min. ${ }^{b}$ Isolated yields. ${ }^{c}$ Determined by HPLC with a chiral stationary phase. ${ }^{d}$ At $23^{\circ} \mathrm{C}$.

Scheme 2 Streamlined synthesis of $\mathrm{Ph}-\mathrm{Cp}^{\mathrm{x}}$ ligand 9. 
alkenes like cyclopentene or dihydrofuran were unreactive under these conditions.

A larger scale allowed for a more concentrated reaction and the catalyst loading of $1 \mathrm{a}$ could be conveniently lowered to 1 mol\% Ru (eqn (1)).

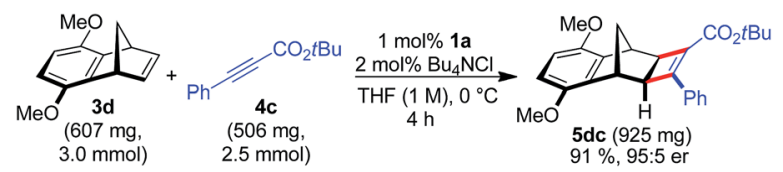

When using norbornadiene as substrate, ruthenium complex 11 (74\% based on the employed amount of 1a) was isolated besides cyclobutene 5bc (Scheme 3a). The neutral complex $\mathbf{1 1}$ is remarkably stable and was isolated by silica gel chromatography and showed no sign of instability in air. The ruthenium center of $\mathbf{1 1}$ binds to one norbornadiene group and to a chloride atom. This well-defined complex allowed probing the chloride anion effect. Indeed, without any additional $\mathrm{Bu}_{4} \mathrm{NCl}$, complex 11 provides 5 bc in identical enantioselectivity (Scheme 3a). The dissociation of the tightly bound norbornadiene to free the required coordinating sites for catalysis slightly attenuates the reactivity (Scheme $3 \mathrm{~b}$ ).

The X-ray structure of $\mathbf{1 1}$ provides important details on the binding pocket of the chloride ligated $\mathrm{Cp}^{\mathrm{x}} \mathrm{Ru}$ catalysts (Scheme 4). Chloride occupies a coordination site at the ruthenium center allowing only for one single alkyne molecule to be coordinated in a productive cycle. In contrast, with the third vacant site of cationic complexes, a second alkyne molecule could coordinate causing an unselective participation leading to a racemic product as previously observed (Table 1, entry 1). Chloride, as smallest ligand, is oriented towards the naphthyl backbone. This differentiates the remaining two coordination sites. From the front view of 11, the left one is wide open allowing for the bulky bicyclic alkene to bind with its exocyclic face, due to orbital distortion of the double bond. In contrast,

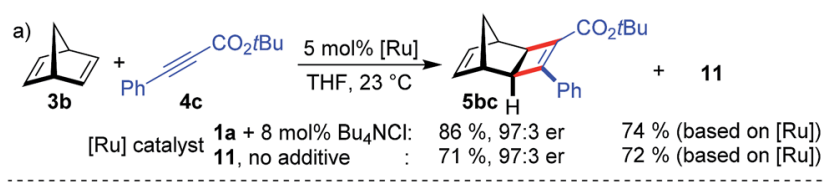

Ru-complex 11:
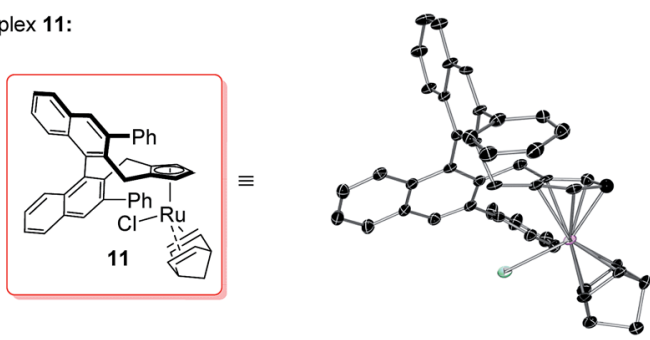

b)

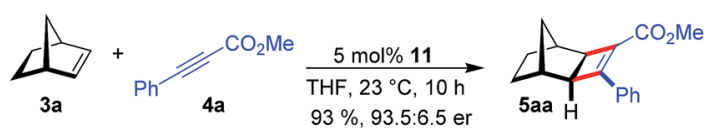

Scheme 3 Isolation of the neutral $\mathrm{Cp}^{\mathrm{x}} \mathrm{RuCl}$ complex 12 and its recycling in catalysis.

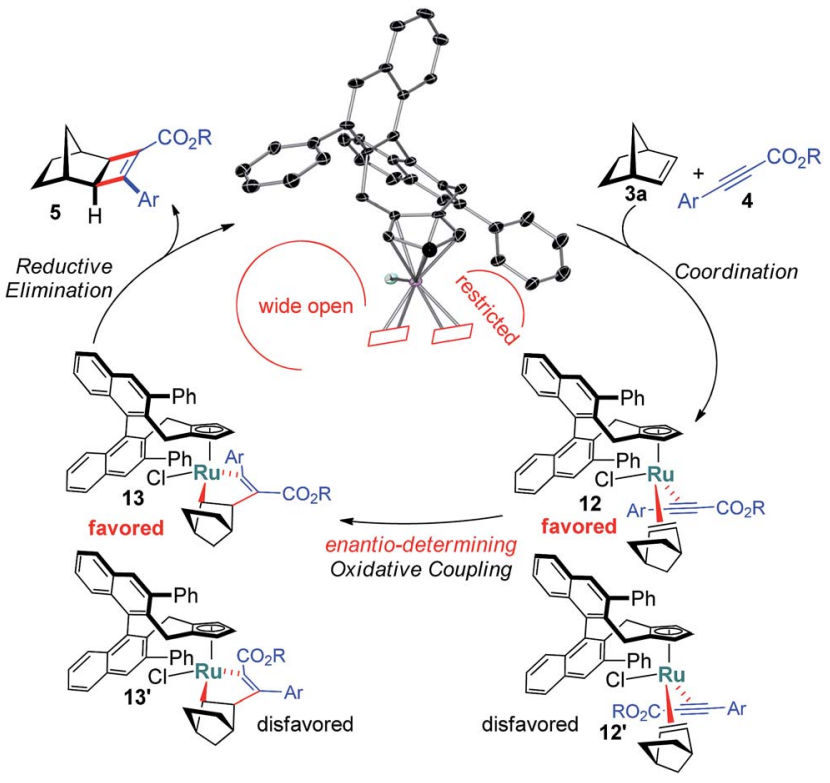

Scheme 4 Selectivity model for the enantioselective cyclobutene formation.

the right one is clearly restricted by the guiding phenyl group of the ligand. The alkyne with its rod-like geometry fits well. Within these boundaries, the enantioselection can be rationalised. Computational studies by Goddard with $\mathrm{Cp} * \mathrm{RuCl}$ indicated a significantly lower transition state energy for the ruthenacyclopentene formation in which the ester points away from the chloride atom. ${ }^{\mathbf{1 4}}$ Subsequent reductive elimination expels cyclobutene 5 and regenerates the initial complex. The complete picture fits well with the observations of higher selectivities of alkynes with bulkier esters, which point into the open space away from the complex.

\section{Conclusions}

In summary, we report a chiral neutral $\mathrm{Cp}^{\mathrm{x}} \mathrm{Ru}(\mathrm{II}) \mathrm{Cl}$ complex providing superior catalytic reactivity than the gold-standard $\mathrm{Cp}^{*} \mathrm{Ru}(\mathrm{COD}) \mathrm{Cl}$ complex. We have shown the excellent reactivity and selectivity of the catalyst for enantioselective [2+2]-cycloadditions leading to strained chiral cyclobutenes at catalyst loadings as low as $1 \mathrm{~mol} \%$. The bound chloride anion transforms the completely unselective cationic catalyst into the highly enantioselective neutral version. Moreover by adding norbornadiene at the end of the reaction, the catalyst can be recovered and subsequently reused. Finally, a streamlined $\mathrm{C}-\mathrm{H}$ functionalisation approach allows an efficient preparation of the chiral cyclopentadienyl ligand.

\section{Acknowledgements}

This work is supported by the Swiss National Science Foundation (No. 157741). We thank Dr R. Scopelliti and Dr F. F. Tirani for X-ray analysis of $5 \mathbf{a g}-\mathrm{CO}_{2} \mathbf{H}$ and 11. 


\section{Notes and references}

1 (a) S.-I. Murahashi, Ruthenium in Organic Synthesis, WileyVCH, Weinheim, 2004; (b) C. Bruneau and P. H. Dixneuf, Ruthenium in Catalysis, Springer, Berlin, 2014.

2 G. C. Vougioukalakis and R. H. Grubbs, Chem. Rev., 2010, 110, 1746-1787.

3 (a) R. Noyori and T. Ohkuma, Angew. Chem., Int. Ed., 2001, 40, 40-73; for $\mathrm{C}-\mathrm{C}$ bond formation via transfer hydrogenation see: $(b)$ F. Perez, S. Oda, L. M. Geary and M. J. Krische, Top. Curr. Chem., 2016, 374, 365-387.

4 (a) B. M. Trost, M. U. Frederiksen and M. T. Rudd, Angew. Chem., Int. Ed., 2005, 44, 6630-6666; (b) B. M. Trost, Acc. Chem. Res., 2002, 35, 695-705; (c) B. M. Trost, F. D. Toste and A. B. Pinkerton, Chem. Rev., 2001, 101, 2067-2096.

5 (a) B. M. Trost and M. C. Ryan, J. Am. Chem. Soc., 2016, 138, 2981-2984; (b) B. M. Trost, M. C. Ryan and D. Maurer, Org. Lett., 2016, 18, 3166-3169; (c) B. M. Trost, M. C. Ryan, M. Rao and T. Z. Markovic, J. Am. Chem. Soc., 2014, 136, 17422-17425; (d) B. M. Trost, M. Rao and A. P. Dieskau, J. Am. Chem. Soc., 2013, 135, 18697-18704; (e) S. Tanaka, T. Seki and M. Kitamura, Angew. Chem., Int. Ed., 2009, 48, 8948-8951; (f) K. Fukamizu, Y. Miyake and Y. Nishibayashi, J. Am. Chem. Soc., 2008, 130, 10498-10499; $(g)$ N. Dodo, Y. Matsushima, M. Uno, K. Onitsuka and S. Takahashi, J. Chem. Soc., Dalton Trans., 2000, 35-41.

6 (a) C. G. Newton, D. Kossler and N. Cramer, J. Am. Chem. Soc., 2016, 138, 3935-3941; (b) B. Ye and N. Cramer, Acc. Chem. Res., 2015, 48, 1308-1318; (c) B. Ye and N. Cramer, J. Am. Chem. Soc., 2013, 135, 636-639; (d) B. Ye and N. Cramer, Science, 2012, 338, 504-506.

7 D. Kossler and N. Cramer, J. Am. Chem. Soc., 2015, 137, 12478-12481.

8 S. Dérien and P. H. Dixneuf, J. Organomet. Chem., 2004, 689, 1382-1392.

9 K. Fagnou and M. Lautens, Angew. Chem., Int. Ed., 2002, 41, 26-47.

10 S. M. Rummelt, K. Radkowski, D.-A. Roşca and A. Fürstner, J. Am. Chem. Soc., 2015, 137, 5506-5519.

11 (a) T.-a. Mitsudo, H. Naruse, T. Kondo, Y. Ozaki and Y. Watanabe, Angew. Chem., Int. Ed., 1994, 33, 580-581; (b) M. Lautens, W. Klute and W. Tam, Chem. Rev., 1996, 96, 49-92; for a cobalt catalysed [2+2] reaction see: (c) T. G. Baik, A. L. Luis, L.-C. Wang and M. J. Krische, J. Am. Chem. Soc., 2001, 123, 6716-6717; (d) L.-C. Wang, H.-Y. Jang, Y. Roh, V. Lynch, A. J. Schultz, X. Wang and M. J. Krische, J. Am. Chem. Soc., 2002, 124, 9448-9453.
12 (a) M. Eisold, A. N. Baumann, G. M. Kiefl, S. T. Emmerling and D. Didier, Chem.-Eur. J., 2016, DOI: 10.1002/ chem.201604585; (b) A. Misale, S. Niyomchon and N. Maulide, Acc. Chem. Res., 2016, 49, 2444-2458; (c) Y. Xu, M. L. Conner and M. K. Brown, Angew. Chem., Int. Ed., 2015, 54, 11918-11928.

13 (a) T. Seiser, T. Saget, D. N. Tran and N. Cramer, Angew. Chem., Int. Ed., 2011, 50, 7740-7752; (b) E. Lee-Ruff and G. Mladenova, Chem. Rev., 2003, 103, 1449-1484; (c) J. C. Namyslo and D. E. Kaufmann, Chem. Rev., 2003, 103, 1485-1538.

14 P. Liu, W. Tam and J. D. Goddard, Tetrahedron, 2007, 63, 7659-7666.

15 (a) W. Tam and N. Cockburn, Synlett, 2010, 1170-1189; (b) R. R. Burton and W. Tam, J. Org. Chem., 2007, 72, 73337336; (c) R. W. Jordan, K. Villeneuve and W. Tam, J. Org. Chem., 2006, 71, 5830-5833; (d) R. W. Jordan and W. Tam, Tetrahedron Lett., 2002, 43, 6051-6054; (e) R. W. Jordan and W. Tam, Org. Lett., 2001, 3, 2367-2370.

16 K. Villeneuve and W. Tam, Angew. Chem., Int. Ed., 2004, 43, 610-613.

17 T. Shibata, K. Takami and A. Kawachi, Org. Lett., 2006, 8, 1343-1345.

18 B.-M. Fan, X.-J. Li, F.-Z. Peng, H.-B. Zhang, A. S. C. Chan and Z.-H. Shao, Org. Lett., 2010, 12, 304-306.

19 (a) J. A. Varela, S. G. Rubín, C. González-Rodríguez, L. Castedo and C. Saá, J. Am. Chem. Soc., 2006, 128, 92629263; for recent examples of counterion effects in $\mathrm{Rh}$ catalysis see: $(b)$ X. Wu, Z. Chen, Y.-B. Bai and V. M. Dong, J. Am. Chem. Soc., 2016, 138, 12013-12016; (c) S. K. Murphy, J.-W. Park, F. A. Cruz and V. M. Dong, Science, 2015, 347, 56-60.

$20\left[\mathrm{Cp}^{\mathrm{x}}(\mathrm{Ph}) \mathrm{Ru}(\mathrm{CO})(\mathrm{MeCN})_{2}\right] \mathrm{PF}_{6}: \tilde{v}(\mathrm{CO})=1992 \mathrm{~cm}^{-1},\left[\mathrm{Cp}^{\mathrm{x}}(\mathrm{OMe})\right.$ $\left.\mathrm{Ru}(\mathrm{CO})(\mathrm{MeCN})_{2}\right] \mathrm{PF}_{6}: \tilde{v}(\mathrm{CO})=1989 \mathrm{~cm}^{-1}$.

21 T. Ooi, M. Kameda and K. Maruoka, J. Am. Chem. Soc., 2003, 125, 5139-5151.

22 (a) H. Egami, K. Sato, J. Asada, Y. Kawato and Y. Hamashima, Tetrahedron, 2015, 71, 6384-6388; (b) T. Hoshi, E. Nozawa, M. Katano, T. Suzuki and H. Hagiwara, Tetrahedron Lett., 2004, 45, 3485-3487.

23 K. M. Engle, T.-S. Mei, M. Wasa and J.-Q. Yu, Acc. Chem. Res., 2012, 45, 788-802.

24 (a) D.-H. Wang, T.-S. Mei and J.-Q. Yu, J. Am. Chem. Soc., 2008, 130, 17676-17677; (b) H. A. Chiong, Q.-N. Pham and O. Daugulis, J. Am. Chem. Soc., 2007, 129, 9879-9884.

25 (a) K. M. Engle and J.-Q. Yu, J. Org. Chem., 2013, 78, 89278955; (b) D.-H. Wang, K. M. Engle, B.-F. Shi and J.-Q. Yu, Science, 2010, 327, 315-319. 